\title{
Hyperthermia reduces migration of osteosarcoma by suppression of autocrine motility factor
}

\author{
KOSEI NAKAJIMA ${ }^{1}$, TAKASHI YANAGAWA ${ }^{1}$, HIDEOMI WATANABE ${ }^{2}$ and KENJI TAKAGISHI $^{1}$ \\ Departments of ${ }^{1}$ Orthopedic Surgery, Graduate School of Medicine and ${ }^{2}$ Physical Therapy, \\ Graduate School of Health Science, Gunma University, Maebashi, Gunma, Japan
}

Received July 10, 2012; Accepted August 27, 2012

DOI: $10.3892 /$ or.2012.2066

\begin{abstract}
Autocrine motility factor (AMF) plays an important role in the development of metastasis by regulating tumor cell motility. The expression of AMF is associated with metastasis in malignant musculoskeletal tumors including osteosarcoma. Recent studies indicated that hyperthermia contributes to the improvement of the prognosis of patients with soft tissue sarcomas; however, few reports have evaluated the impact of hyperthermia on tumor cell motility, which is an important factor of metastasis. The purpose of this study was to evaluate the effect of hyperthermia with or without heat shock protein (HSP) inhibitors on the motility and AMF expression in an osteosarcoma cell line. Hyperthermia was carried out at $41^{\circ} \mathrm{C}$ for $24 \mathrm{~h}$. According to microarray results, HSP90, HSP70 and HSP27 expression was upregulated in osteosarcoma cells under hyperthermia. The intracellular, secreted AMF, mRNA of AMF and cell motility were evaluated by western blotting, ELISA, RT-PCR, wound healing and phagokinetic track assays, respectively. The protein secretion and mRNA levels of AMF and tumor cell motility were significantly decreased by hyperthermia. Of note, the downregulated AMF expression and motility were recovered by the addition of an HSP27 inhibitor. By contrast, the HSP90 and HSP70/72/105 inhibitors had no effect on AMF expression and motility downregulated by hyperthermia. In conclusion, hyperthermia reduced AMF expression and tumor cell motility via HSP27 and may therefore be applied as osteosarcoma treatment.
\end{abstract}

\section{Introduction}

Osteosarcoma is the most common primary malignant bone tumor; it occurs during adolescence and is ranked eighth in

Correspondence to: Dr Takashi Yanagawa, Department of Orthopedic Surgery, Graduate School of Medicine, Gunma University, 3-39-22 Showa, Maebashi, Gunma 371-8511, Japan

E-mail: tyanagaw@med.gunma-u.ac.jp

Abbreviations: AMF, autocrine motility factor; PGI, phosphoglucose isomerase; HSP, heat shock protein; MMP, matrix metalloproteinase

Key words: autocrine motility factor, heat shock protein, hyperthermia, metastasis, motility, osteosarcoma general incidence among childhood cancers. The overall 5-year survival rate for osteosarcoma ranges from 50 to $80 \%$ (1-5). Despite adequate surgical removal and chemotherapy at an early stage of osteosarcoma, some patients experience distant metastasis to the lung, bone or other organs; therefore, prevention of the invasion and metastasis of osteosarcoma is crucial in improving the prognosis of patients. To combat the aggressive potential of osteosarcoma, various factors associated with invasion and metastasis have been identified. Among them, autocrine motility factor (AMF) plays an important role in metastasis. AMF is secreted by tumor cells and stimulates the potential of proliferation $(6)$, migration $(7,8)$, angiogenesis $(9,10)$ and resistance to apoptosis $(11,12)$. In previous studies, molecular cloning and sequencing identified phosphoglucose isomerase (PGI) as AMF (13). PGI is an essential cytosolic enzyme of sugar metabolism and plays a key role in both glycolysis and the gluconeogenesis pathway, catalyzing the interconversion of glucose 6-phosphate and fructose 6-phosphate in both normal and tumor cells (14). PGI is secreted extracellularly from various tumors, not from normal cells, and behaves as AMF (15-17). Elevated serum AMF levels in malignant tumors, including the gastrointestinal tract (18), colorectum (19), breast (20), and lung cancer (21), are associated with cancer progression and metastasis. In addition, recent studies indicated that upregulated AMF expression is involved in the metastasis of osteosarcoma (22). Moreover, silencing AMF causes mesenchymal-to-epithelial transition and completely prevents pulmonary metastasis of osteosarcoma (23). Thus, suppressing AMF appears to be an appropriate treatment to control tumor invasion and metastasis; however, inhibition of AMF expression throughout the body may have a risk. AMF works as PGI, which is a critical molecule for glucose metabolism in all kinds of cells and, therefore, suppressing AMF in the whole body may inhibit a patient's ability to metabolize glucose. This is one of the reasons why clinical trials to suppress AMF have not been performed.

Hyperthermia is an effective local adjuvant therapy for carcinomas and sarcomas. A randomized phase III trial showed that regional hyperthermia combined with neoadjuvant chemotherapy for soft tissue sarcomas had better local progression-free survival than chemotherapy alone (24). Several reports have suggested that hyperthermia for osteosarcoma achieved an effective response, including the induction of apoptosis (25) and inhibition of tumor proliferation $(26,27)$ and DNA synthesis (27) in vitro. Regional hyperthermia using 
an alternating magnetic field reduced the pulmonary metastasis of osteosarcoma in an in vivo study (28). In the present study, we examined the involvement of AMF and heat shock genes including heat shock protein (HSP) and tumor cell motility in osteosarcoma cells under normal and hyperthermic conditions.

\section{Materials and methods}

Antibodies and reagents. Anti-AMF/PGI mouse monoclonal antibody was purchased from ProMab Biotechnologies Inc. (Richmond, CA, USA) and anti- $\beta$-actin mouse monoclonal antibody was purchased from Sigma-Aldrich Inc. (St. Louis, MO, USA). 17-AAG, a heat shock protein (HSP)90 inhibitor, KNK437, an HSP70/72/105 inhibitor, and KRIBB-III, an HSP27 inhibitor were purchased from Selleck Chemicals Inc. (Houston, TX, USA), Merck Inc. (Darmstadt, Germany) and Sigma-Aldrich Inc., respectively. The horseradish peroxidase (HRP)-conjugated goat anti-mouse antibody was purchased from Zymed Inc. (South San Francisco, CA, USA). The enzyme-linked immunosorbent assay kit for human glucose 6 phosphate isomerase was purchased from Uscn Life Science Inc. (Wuhan, China).

Cell culture. The human osteosarcoma cell line HuO9 was kindly provided by Dr T. Hotta (Niigata University, Niigata, Japan) and grown in RPMI-1640 supplemented with $10 \%$ heatinactivated fetal bovine serum (FBS). The cells were maintained at $37^{\circ} \mathrm{C}$ in a humidified atmosphere of $5 \% \mathrm{CO}_{2}$ and $95 \%$ air.

Treatment with hyperthermia and HSP inhibitors. Culture with hyperthermia was carried out at $41^{\circ} \mathrm{C}$ for $24 \mathrm{~h}$ in a $5 \%$ $\mathrm{CO}_{2}$ incubator. Prior to hyperthermia exposure, cells were washed with phosphate-buffered saline (PBS), and fresh medium was added. The concentrations of HSP inhibitors were less than the cytotoxic level shown in previous reports, with $10 \mathrm{nM}$ for 17-AAG (29) and KRIBB-III (30) and $10 \mu \mathrm{M}$ for KNK437 (31).

DNA microarray analysis. $\mathrm{HuO} 9$ cells were separated into two conditions, 41 and $37^{\circ} \mathrm{C}$. The isolated total-RNA of the cells in each condition was used for synthesis of cDNA, which was labeled with biotin and hybridized with the GeneChip Array, Human Genome U133 Plus 2.0 Array (Affymetrix Inc., Santa Clara, CA, USA). The array was scanned with a GeneChip 3000 scanner. The signal intensities from hybridized cDNA were quantified. The final processed data were obtained by the global normalization method using GCOS software.

RT-PCR analysis. Total-RNA was isolated from hyperthermia-treated $\mathrm{HuO} 9$ cells with or without HSP inhibitors for $24 \mathrm{~h}$ using Isogen (Wako Pure Chemical Industries, Osaka, Japan). The cDNA was generated using a SuperScript III First-strand Synthesis SuperMix (Invitrogen Inc., Carlsbad, CA, USA) as recommended in the manufacturer's protocol. The products of reverse transcription reactions were used for PCR. $\beta$-actin was used as an internal control. The number of amplification cycles for PGI/AMF, $\beta$-actin genes, was 25 , respectively, which was selected to allow linear amplification of the cDNA under study. The primer sequences and their respective $\mathrm{PCR}$ fragment lengths were: $\mathrm{PGI} / \mathrm{AMF}$, 5'-AATGCAGAGACGGCGAAGAAG-3' (forward) and 5'-ACGAGAAGAGAAAGGGGAGTC-3' (reverse) (1066 bp); $\beta$-actin, 5'-TGACGCGGTCACCCACACTGTGCCCAT-3' (forward) and 5'-CTAGAAGCATTTGCGGTGGGAGGG-3' (reverse) (610 bp). PCR products were electrophoresed on $1 \%$ agarose gels, stained with ethidium bromide and photographed.

Sampling intracellular AMF from cell cultures. HuO9 cells cultured on $10-\mathrm{cm}$ dishes were treated by hyperthermia with or without HSP inhibitors for $24 \mathrm{~h}$ and then transferred to $37^{\circ} \mathrm{C}$ for $24 \mathrm{~h}$ in a $5 \% \mathrm{CO}_{2}$ incubator. Intracellular proteins were collected by scraping and lysed in radioimmune precipitation assay buffer (20 mM Tris-HCl, pH 7.4, $150 \mathrm{mM} \mathrm{NaCl}, 10 \mathrm{mM}$ EDTA, $1 \%$ of NP-40, Triton X-100, sodium deoxycholate) containing $1 \mathrm{mM}$ phenylmethylsulfonyl fluoride. After cell lysates were centrifuged, the supernatants were subjected to SDS-PAGE to investigate the expression of intracellular AMF/ PGI and $\beta$-actin. The protein concentration of each sample was determined using Bio-Rad protein assay reagent (Bio-Rad Laboratories Inc., Hercules, CA, USA).

Western blot analysis. All protein samples were separated on $10 \%$ SDS-PAGE gels and transferred to a polyvinylidene difluoride membrane (Millipore Inc., Billerica, MA, USA). Western blotting was carried out by the SNAP-id protein detection system (Millipore Inc.) according to the manufacturer's instructions. The membrane was blocked with Bløk, a noise-cancelling reagent (Millipore Inc.), for $30 \mathrm{sec}$ at room temperature. The blocked membrane was incubated with diluted primary antibodies (AMF/PGI 1:1,000, $\beta$-actin 1:1,000) for $10 \mathrm{~min}$. Following extensive washing, anti-mouse HRP-conjugated secondary antibody (1:1,000) was added and incubated for $10 \mathrm{~min}$. Proteins were visualized using a chemiluminescence (ECL) system.

ELISA. To examine the concentration of secreted AMF, an enzyme-linked immunosorbent assay kit for human glucose 6 phosphate isomerase (Uscn Life Science Inc.) was used according to the manufacturer's instructions. The secreted protein was isolated from RPMI with $10 \%$ FBS. HuO9 cells were expanded on $10-\mathrm{cm}$ dishes as a confluent monolayer. After the cells had been exposed to hyperthermia with or without HSP inhibitors for $24 \mathrm{~h}$, the medium was replaced with $5 \mathrm{ml}$ RPMI with $10 \%$ FBS. Supernatants were collected for ELISA after the cells had been incubated at $37^{\circ} \mathrm{C}$ for $24 \mathrm{~h}$.

Wound healing assay. Horizontal motility was measured by the wound-healing assay. The surface of the cultured $\mathrm{HuO} 9$ cell monolayer in each prepared well was wounded by a pipette tip and the medium was replaced. After 24 and $48 \mathrm{~h}$ of incubation, the wounded area was photographed and the wound area filled was calculated using the formula: $\%$ wound area filled $=$ (average wound width before incubation - average wound width after incubation / average wound width before incubation) x 100 .

Phagokinetic track assay. Random cell motility was measured by the phagokinetic track assay as previously described. Uniform carpets of gold particles were prepared on coverslips coated with $1.0 \%$ bovine serum albumin (BSA) by fixing with 
Table I. HSP genes > 2-fold upregulated by hyperthermia compared with the control sample.

\begin{tabular}{lccc}
\hline Gene name & $\begin{array}{c}\text { Gene } \\
\text { symbol }\end{array}$ & $\begin{array}{c}\text { GenBank } \\
\text { accession no. }\end{array}$ & $\begin{array}{c}\text { Fold } \\
\text { change }\end{array}$ \\
\hline $\begin{array}{l}\text { Heat shock 105-kDa/ } \\
\begin{array}{l}\text { 110kDa protein 1 } \\
\text { Heat shock 70-kDa } \\
\text { protein 1A }\end{array}\end{array}$ HSPH1 & NM_006644 & 2.77 \\
$\begin{array}{l}\text { Heat shock 70-kDa } \\
\text { protein 1B }\end{array}$ & HSPA1B & NM_005346 & 4.4 \\
$\begin{array}{l}\text { Heat shock 70-kDa } \\
\text { protein 6 (HSP70B') }\end{array}$ & HSPA6 & NM_002155 & 6.67 \\
$\begin{array}{l}\text { Heat shock 27-kDa } \\
\text { protein 1 }\end{array}$ & HSPB1 & NM_001540 & 2.84 \\
$\begin{array}{l}\text { Heat shock 22-kDa } \\
\text { protein 8 }\end{array}$ & HSPB8 & AF133207 & 2.41 \\
\hline
\end{tabular}

$100 \%$ ethanol and warm air drying. The treated coverslips were then embedded with colloidal gold particles and placed in 35-mm tissue culture dishes. Then, 3,000 cells in suspension culture were added to the plates. After $24 \mathrm{~h}$, the phagokinetic tracks were visualized using dark field illumination with a Nikon inverted microscope. The area cleared of gold particles by $\geq 30$ cells was measured using NIH Image $\mathrm{J}$.

Statistical analysis. Statistical analysis was performed using SPSS 17.0 software (SPSS Inc., Chicago, IL, USA). Wound healing and phagokinetic track motility assays were analyzed using analysis of variance (ANOVA) and the significance of individual differences was evaluated using the Tukey HSD if ANOVA was significant.

\section{Results}

Upregulated heat shock proteins in osteosarcoma cells under hyperthermia. HSP has several subtypes, HSP110/105, HSP90, HSP72/70, HSP60, HSP40, HSP27, HSP22, and HSP10. We confirmed the molecular responses of HuO9 cells under hyperthermia using a microarray. More than 2-fold upregulated genes among HSPs compared to the control were HSP105, HSP70, HSP27 and HSP22 (Table I). Since there are no reports showing that HSP22 is involved in cell migration, cancer metastasis, invasion, or proliferation, KNK437, an HSP70/72/105 inhibitor, and KRIBB-III, an HSP27 inhibitor, were selected in this study. 17AAG, an HSP90 inhibitor, was also selected as this subtype has been well examined as a molecular target drug for cancer therapy $(32,33)$, although the increase of HSP90 gene expression was slight (1.82-fold).

Hyperthermia reduces $m R N A$ level and secretion of $A M F$. To analyze the effect of hyperthermia on AMF expression, the $\mathrm{HuO} 9$ osteosarcoma cell line was exposed to hyperthermia at $41^{\circ} \mathrm{C}$ and to normal conditions at $37^{\circ} \mathrm{C}$ for $24 \mathrm{~h}$. The level of mRNA, intracellular protein and secreted protein was determined by RT-PCR, western blotting and ELISA, respectively. The HuO9 osteosarcoma cell line showed a decrease in the

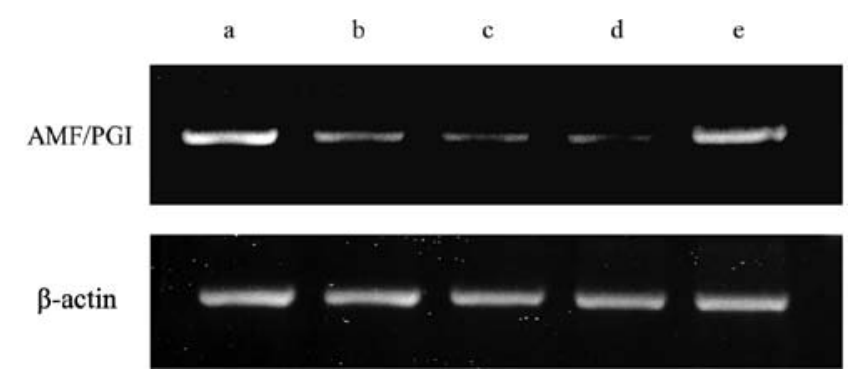

Figure 1. AMF mRNA expression of the $\mathrm{HuO} 9$ osteosarcoma cell line under hyperthermia with or without HSP inhibitors. Heat shock induced AMF mRNA suppression, which was recovered by the HSP27 inhibitor, KRIBB-III. Representative results of 3 different experiments are shown. a, control; b, hyperthermia; c, hyperthermia + 17-AAG; d, hyperthermia + KNK437; e, hyperthermia + KRIBB-III.

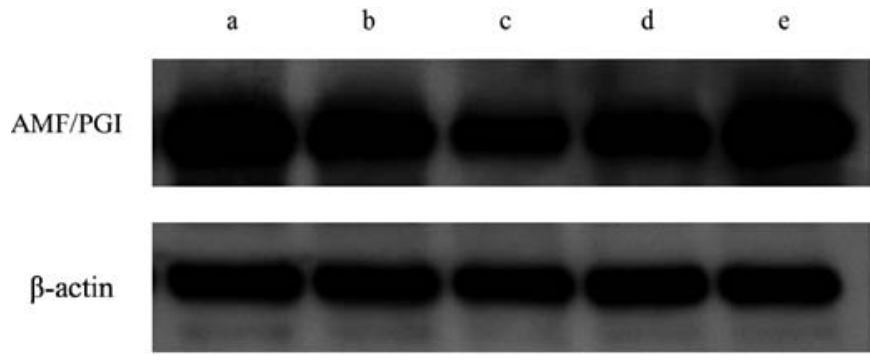

Figure 2. Intracellular AMF expression of the $\mathrm{HuO} 9$ osteosarcoma cell line under hyperthermia with or without HSP inhibitors. Similar to mRNA, intracellular AMF was reduced by hyperthermia and recovered by the HSP27 inhibitor. Representative results of 3 different experiments are shown. a, control; b, hyperthermia; c, hyperthermia + 17-AAG; d, hyperthermia + KNK437; e, hyperthermia + KRIBB-III.

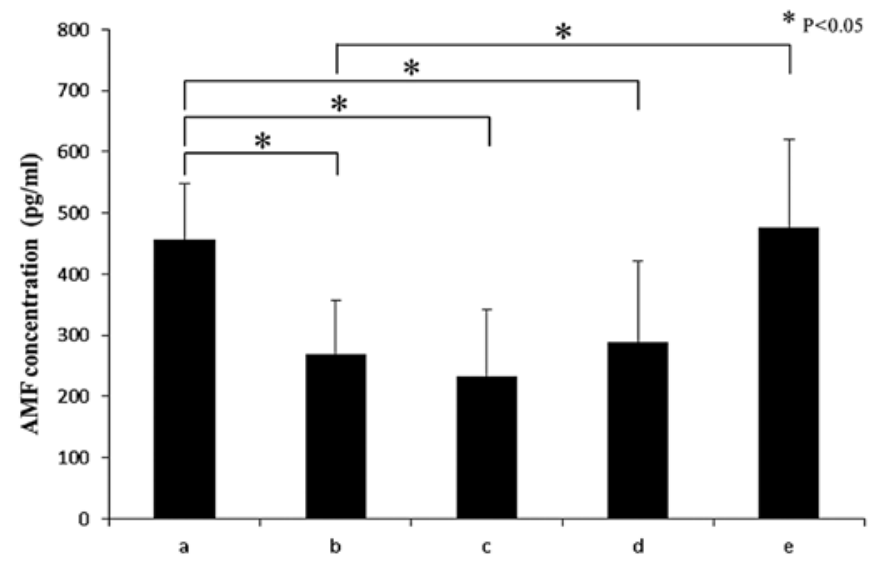

Figure 3. Secreted AMF levels measured with ELISA under hyperthermia with or without HSP inhibitors. AMF secretion was inhibited by hyperthermia and recovered to the level of the control by the addition of HSP27. Data are presented as the mean \pm SD of 6 different experiments. a, control; b, hyperthermia; c, hyperthermia + 17-AAG; d, hyperthermia + KNK437; e, hyperthermia + KRIBB-III.

mRNA level of AMF under hyperthermic conditions (Fig. 1). Western blotting revealed slight downregulation of intracellular AMF compared with the control sample (Fig. 2). Secreted AMF measured with ELISA was significantly downregulated by hyperthermia compared with the control [hyperthermia; mean 269.0 \pm 87.4 (SD) vs control; mean 456.7 $\pm 90.5 \mathrm{p}=0.047$ ] (Fig. 3). Previous reports showed that the amount of secreted 


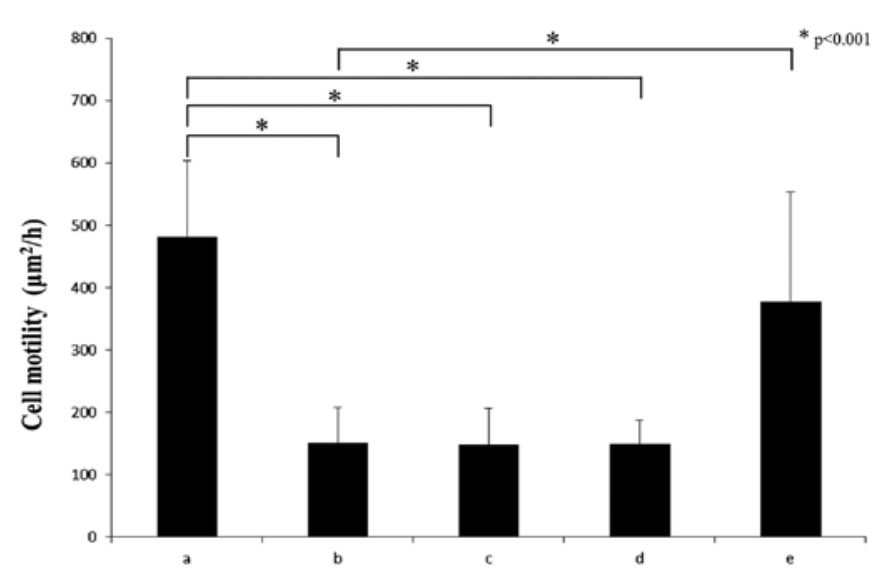

Figure 4. The results of a phagokinetic track assay for $\mathrm{HuO} 9$ osteosarcoma cells incubated under hyperthermia with or without HSP inhibitors. The motility paralleled the AMF expression presented in Figs. 1-3. Asterisk $\left(^{*}\right)$ indicates a significant difference from the control group ( $<<0.001)$. a, control; b, hyperthermia; c, hyperthermia + 17-AAG; d, hyperthermia + KNK437; e, hyperthermia + KRIBB-III.

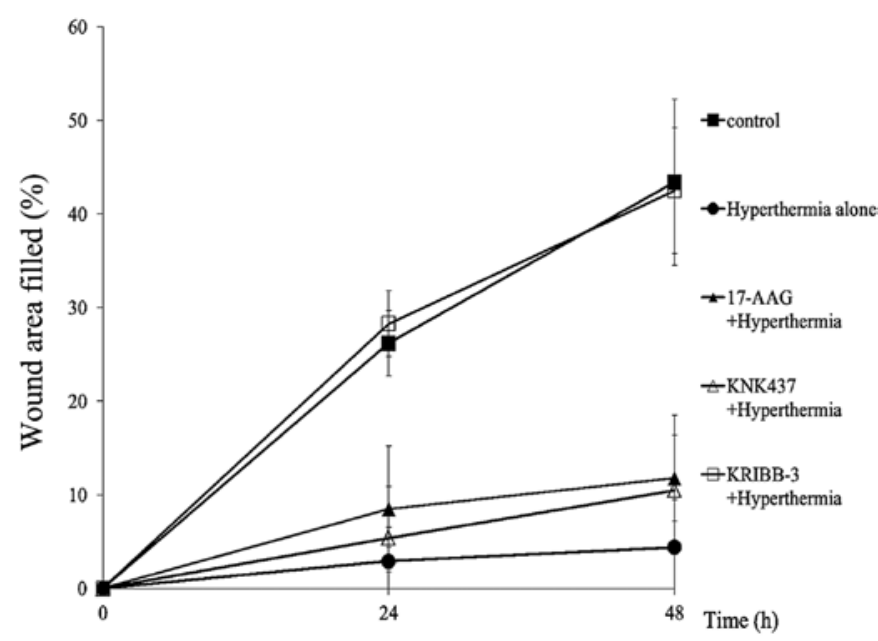

Figure 5. Results of the wound healing assay. Graph shows the effect of hyperthermia with or without HSP inhibitors on the cell motility of the $\mathrm{HuO} 9$ osteosarcoma cell line. Results were quantified by NIH Image J. Data are presented as the mean $\pm \mathrm{SD}$ of 3 different experiments.

AMF was mainly dependent on the mRNA level, not on the intracellular protein level (15-17); therefore, we concluded that hyperthermia reduced the expression of mRNA of AMF and subsequently suppressed the secretion of AMF.

Hyperthermia reduces the motility of osteosarcoma. The motility of osteosarcoma cells was significantly decreased under hyperthermia compared to the control sample at a normal temperature. The phagokinetic track assay showed that random motility of $\mathrm{HuO} 9$ cells was significantly suppressed by hyperthermia ( $\mathrm{p}<0.001)$ (Fig. 4). Furthermore, the woundhealing assay revealed the significant suppression of horizontal motility under hyperthermia. The difference was apparent at $24 \mathrm{~h}$ (hyperthermia; mean $2.9 \pm 3.6$ vs control; mean $26.2 \pm 3.5$ $\mathrm{p}=0.004$ ) and at $48 \mathrm{~h}$ (hyperthermia; mean $4.4 \pm 5.1 \mathrm{vs}$ control; mean $43.4 \pm 8.9 \mathrm{p}=0.001$ ) after hyperthermia (Fig. 5).

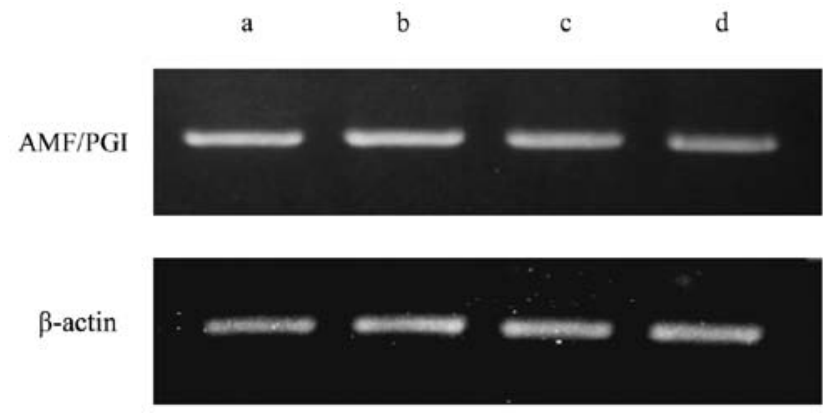

Figure 6. AMF mRNA expression of the $\mathrm{HuO} 9$ osteosarcoma cell line under normal conditions with or without HSP inhibitors. The expression of AMF was not affected by HSP inhibitors under normal conditions. Representative results of 3 different experiments are shown. a, control; b, hyperthermia + 17-AAG; c, hyperthermia + KNK437; d, hyperthermia + KRIBB-III.

Effect of HSP inhibitors on AMF expression and motility under hyperthermic and normal conditions. To explore which HSP pathways play an important role in the regulation of AMF under hyperthermia, we treated $\mathrm{HuO} 9$ cells with various HSP inhibitors during hyperthermic exposure. The AMF mRNA level downregulated by hyperthermia was recovered to almost the same level at $37^{\circ} \mathrm{C}$ by the addition of an HSP27 inhibitor, KRIBB-III (Fig. 1). Western blotting and ELISA also showed the recovery of intracellular and secreted AMF by the addition of KRIBB-III under hyperthermic conditions, as expected ( $\mathrm{p}=0.024)$ (Figs. 2 and 3). These results suggest that the downregulation of AMF expression under hyperthermia is associated with HSP27. As shown in Figs. 4 and 5, the recovery of cell motility was observed under hyperthermic conditions with KRIBB-III by the phagokinetic track $(\mathrm{p}<0.001)$ and wound-healing assay, respectively. Meanwhile, an HSP90 inhibitor, 17-AAG, and an HSP70/72/105 inhibitor, KNK437, had no statistically significant effect on AMF expression and motility compared with hyperthermia alone. No HSP inhibitors affected AMF expression under normal conditions (Fig. 6).

\section{Discussion}

In the present study, we discovered that hyperthermia reduced the mRNA level of AMF, secreted AMF and the motility of osteosarcoma cells. The difference in the amount of secreted AMF between the hyperthermia-treated sample and control was approximately $180 \mathrm{pg} / \mathrm{ml}$, which appeared sufficient to suppress cell motility since a previous study indicated that addition of AMF $100 \mathrm{pg} / \mathrm{ml}$ enhanced motility by 1.5 -fold $(7,13)$. A few reports have described the mechanisms of how hyperthermia affects tumor cell migration, although there have been many reports on thermal therapy preventing tumor cell proliferation. Sato et al reported that hyperthermia suppressed the invasion of fibrosarcoma by inhibiting the production of membrane type-1 matrix metalloproteinase (MMP) and proMMP-2 activity (34). In the present study, we found that a new mechanism was involved in the suppression of osteosarcoma cell motility under hyperthermia via AMF downregulation.

To date, no clinically available agents inhibiting AMF have been reported, although some articles have reported that silencing AMF by RNA interference $(35,36)$ or hammerhead 
ribozyme (23) could inhibit metastasis and the invasion of malignant tumors. Since AMF works as PGI, which plays an important role in glucose metabolism not only in tumors but also in normal cells $(15,37,38)$, complete block of AMF/PGI throughout the body may be harmful or even lethal for normal cells, compelling us to identify procedures that regulate AMF expression locally. Hyperthermia is well known as a clinically available modality for cancer therapy. Regional hyperthermia combined with neo-adjuvant chemotherapy for soft-tissue sarcomas showed better local progression-free survival than chemotherapy alone in a randomized study (24). Hyperthermic isolated limb perfusion with pre-operative chemotherapy for osteosarcoma patients achieved a good response compared to chemotherapy without hyperthermia (39). We expect that regional hyperthermia of osteosarcomas can control AMF secretion from tumor cells without affecting the glucose metabolism throughout the body and prevent tumor invasion and metastasis.

Little is known about the regulatory mechanism of AMF expression as promoter region analysis of AMF remains insufficient, except for one report showing that a minisatellite in intron 9 of human PGI genes stimulated transcription from PGI promoter (40). Hypoxia induces AMF expression via HIF-1 $\alpha$ (41); however, there have been no reports on the proteins or conditions that downregulate AMF expression. In our study, reduced AMF expression by hyperthermia was recovered by the addition of the HSP27 inhibitor, which indicates that HSP27 inhibits AMF expression and tumor cell motility under hyperthermia.

HSPs are induced not only by heat shock but also by other pathological conditions and work as molecular chaperones in maintaining cellular homeostasis and contributing to cell survival (42). Mammalian HSPs have been classified into six groups and HSP27 belongs to small HSPs. Largely oligomerized HSP27 works as a chaperone preventing aggregation while a small oligomer of this molecule stabilizes actin filaments (43). In immunohistochemical studies, overexpression of HSP27 was associated with poor prognosis (44) and distant metastasis (45) in osteosarcoma patients and was found at a higher rate in high-grade than low-grade osteosarcomas (45). HSP27 expression was associated with favorable prognosis only in malignant fibrous histiocytoma among many types of cancer (46). Shin et al reported that the HSP27 inhibitor inhibited cancer proliferation and migration by blocking HSP27 phosphorylation under normal conditions (30). There have been several reports on the use of the HSP27 inhibitor under normal conditions, but there are no reports on its use under hyperthermia. We speculated that the discrepancy in the effects of HSP27 on tumor cell migration between our results and previous reports is likely due to a difference in HSP27 function between normal and hyperthermic conditions. Hyperthermia treatment presents a theoretical dilemma; heat shock stress induces various heat shock proteins, the expression of which is related to poor prognosis and the inhibitors of which are clinically used for cancer therapy (43), although thermal treatments have achieved favorable treatment results. Our hypothesis that HSP27 functions depend on temperature (normal or hyperthermia) may resolve the dilemma of hyperthermia treatments. In addition, hyperthermia is expected to be more effective for HSP27-expressing osteosarcoma as
HSP27 has a propensity to suppress tumor migration under hyperthermic conditions.

In conclusion, hyperthermia suppressed the expression of AMF and the motility of the HuO9 osteosarcoma cell line via HSP27. Our results suggest that hyperthermia is effective in preventing the invasion and metastasis of osteosarcoma by reducing AMF, and HSP27 regulates AMF expression under hyperthermia. Therefore, hyperthermia may be a clinical therapeutic modality for osteosarcoma in, for example, adjuvant and palliative therapies.

\section{References}

1. Bielack SS, Kempf-Bielack B, Delling G, et al: Prognostic factors in high-grade osteosarcoma of the extremities or trunk: an analysis of 1,702 patients treated on neoadjuvant cooperative osteosarcoma study group protocols. J Clin Oncol 20: 776-790, 2002.

2. Whelan JS, Jinks RC, McTiernan A, et al: Survival from highgrade localised extremity osteosarcoma: combined results and prognostic factors from three European Osteosarcoma Intergroup randomised controlled trials. Ann Oncol, Oct 19, 2011 (Epub ahead of print) doi: 10.1093/annonc/mdr491.

3. Bacci G, Longhi A, Versari M, Mercuri M, Briccoli A and Picci P: Prognostic factors for osteosarcoma of the extremity treated with neoadjuvant chemotherapy: 15-year experience in 789 patients treated at a single institution. Cancer 106: 1154-1161, 2006.

4. Ferrari S,Smeland S,Mercuri M,etal: Neoadjuvant chemotherapy with high-dose Ifosfamide, high-dose methotrexate, cisplatin, and doxorubicin for patients with localized osteosarcoma of the extremity: a joint study by the Italian and Scandinavian Sarcoma Groups. J Clin Oncol 23: 8845-8852, 2005.

5. Mirabello L, Troisi RJ and Savage SA: Osteosarcoma incidence and survival rates from 1973 to 2004: data from the Surveillance, Epidemiology, and End Results Program. Cancer 115: 1531-1543, 2009.

6. Tsutsumi S, Yanagawa T, Shimura T, et al: Regulation of cell proliferation by autocrine motility factor/phosphoglucose isomerase signaling. J Biol Chem 278: 32165-32172, 2003.

7. Silletti S, Watanabe H, Hogan V, Nabi IR and Raz A: Purification of B16-F1 melanoma autocrine motility factor and its receptor. Cancer Res 51: 3507-3511, 1991.

8. Watanabe H, Kanbe K and Chigira M: Differential purification of autocrine motility factor derived from a murine protein-free fibrosarcoma. Clin Exp Metastasis 12: 155-163, 1994.

9. Funasaka T, Haga A, Raz A and Nagase H: Tumor autocrine motility factor is an angiogenic factor that stimulates endothelial cell motility. Biochem Biophys Res Commun 284: 1116-1125, 2001.

10. Funasaka T, Haga A, Raz A and Nagase H: Autocrine motility factor secreted by tumor cells upregulates vascular endothelial growth factor receptor (Flt-1) expression in endothelial cells. Int J Cancer 101: 217-223, 2002.

11. Tsutsumi S, Hogan V, Nabi IR and Raz A: Overexpression of the autocrine motility factor/phosphoglucose isomerase induces transformation and survival of NIH-3T3 fibroblasts. Cancer Res 63: 242-249, 2003.

12. Haga A, Funasaka T, Niinaka Y, Raz A and Nagase H: Autocrine motility factor signaling induces tumor apoptotic resistance by regulations Apaf-1 and Caspase-9 apoptosome expression. Int J Cancer 107: 707-714, 2003.

13. Watanabe H, Takehana K, Date M, Shinozaki T and Raz A: Tumor cell autocrine motility factor is the neuroleukin/phosphohexose isomerase polypeptide. Cancer Res 56: 2960-2963, 1996.

14. Faik P, Walker JI, Redmill AA and Morgan MJ: Mouse glucose6-phosphate isomerase and neuroleukin have identical $3^{\prime}$ sequences. Nature 332: 455-457, 1988.

15. Niinaka Y, Paku S, Haga A, Watanabe H and Raz A: Expression and secretion of neuroleukin/phosphohexose isomerase/maturation factor as autocrine motility factor by tumor cells. Cancer Res 58: 2667-2674, 1998.

16. Yanagawa T, Watanabe H, Takeuchi T, Fujimoto S, Kurihara $\mathrm{H}$ and Takagishi K: Overexpression of autocrine motility factor in metastatic tumor cells: possible association with augmented expression of KIF3A and GDI-beta. Lab Invest 84: 513-522, 2004. 
17. Yanagawa T, Funasaka T, Tsutsumi S, Raz T, Tanaka N and Raz A: Differential regulation of phosphoglucose isomerase/ autocrine motility factor activities by protein kinase CK2 phosphorylation. J Biol Chem 280: 10419-10426, 2005.

18. Baumann M, Kappl A, Lang T, Brand K, Siegfried W and Paterok E: The diagnostic validity of the serum tumor marker phosphohexose isomerase (PHI) in patients with gastrointestinal, kidney, and breast cancer. Cancer Invest 8: 351-356, 1990.

19. Filella X, Molina R, Jo J, Mas E and Ballesta AM: Serum phosphohexose isomerase activities in patients with colorectal cancer Tumour Biol 12: 360-367, 1991.

20. Bodansky O: Serum phosphohexose isomerase in cancer. II. As an index of tumor growth in metastatic carcinoma of the breast. Cancer 7: 1200-1226, 1954.

21. Patel PS, Raval GN, Rawal RM, et al: Comparison between serum levels of carcinoembryonic antigen, sialic acid and phosphohexose isomerase in lung cancer. Neoplasma 42: 271-274, 1995.

22. Dobashi Y, Watanabe H, Matsubara M, et al: Autocrine motility factor/glucose-6-phosphate isomerase is a possible predictor of metastasis in bone and soft tissue tumours. J Pathol 208: 44-53, 2006.

23. Niinaka Y, Harada K, Fujimuro M, et al: Silencing of autocrine motility factor induces mesenchymal-to-epithelial transition and suppression of osteosarcoma pulmonary metastasis. Cancer Res 70: 9483-9493, 2010.

24. Issels RD, Lindner LH, Verweij J, et al: Neo-adjuvant chemotherapy alone or with regional hyperthermia for localised high-risk soft-tissue sarcoma: a randomised phase 3 multicentre study. Lancet Oncol 11: 561-570, 2010.

25. Alcaide M, Ramírez-Santillán C, Feito MJ, et al: In vitro evaluation of glass-glass ceramic thermoseed-induced hyperthermia on human osteosarcoma cell line. J Biomed Mater Res A 100: 64-71, 2012.

26. Trieb K, Blahovec $\mathrm{H}$ and Kubista B: Effects of hyperthermia on heat shock protein expression, alkaline phosphatase activity and proliferation in human osteosarcoma cells. Cell Biochem Funct 25: 669-672, 2007

27. Shui $\mathrm{C}$ and Scutt A: Mild heat shock induces proliferation, alkaline phosphatase activity, and mineralization in human bone marrow stromal cells and Mg-63 cells in vitro. J Bone Miner Res 16: 731-741, 2001.

28. Shido Y, Nishida Y, Suzuki Y, Kobayashi T and Ishiguro N: Targeted hyperthermia using magnetite cationic liposomes and an alternating magnetic field in a mouse osteosarcoma model J Bone Joint Surg Br 92: 580-585, 2010.

29. Bagatell R, Beliakoff J, David CL, Marron MT and Whitesell L: Hsp90 inhibitors deplete key anti-apoptotic proteins in pediatric solid tumor cells and demonstrate synergistic anticancer activity with cisplatin. Int J Cancer 113: 179-188, 2005.

30. Shin KD, Lee MY, Shin DS, et al: Blocking tumor cell migration and invasion with biphenyl isoxazole derivative KRIBB3, a synthetic molecule that inhibits Hsp27 phosphorylation. J Biol Chem 280: 41439-41448, 2005.

31. Yokota S, Kitahara M and Nagata K: Benzylidene lactam compound, KNK437, a novel inhibitor of acquisition of thermotolerance and heat shock protein induction in human colon carcinoma cells. Cancer Res 60: 2942-2948, 2000.
32. Bagatell R, Gore L, Egorin MJ, et al: Phase I pharmacokinetic and pharmacodynamic study of 17-N-allylamino-17-demethoxygeldanamycin in pediatric patients with recurrent or refractory solid tumors: a pediatric oncology experimental therapeutics investigators consortium study. Clin Cancer Res 13: 1783-1788, 2007.

33. Koga F, Kihara K and Neckers L: Inhibition of cancer invasion and metastasis by targeting the molecular chaperone heat-shock protein 90. Anticancer Res 29: 797-807, 2009.

34. Sato T, Sawaji Y, Matsui N, et al: Heat shock suppresses membrane type 1-matrix metalloproteinase production and progelatinase $\mathrm{A}$ activation in human fibrosarcoma HT-1080 cells and thereby inhibits cellular invasion. Biochem Biophys Res Commun 265: 189-193, 1999.

35. Funasaka T, Hu H, Yanagawa T, Hogan V and Raz A: Downregulation of phosphoglucose isomerase/autocrine motility factor results in mesenchymal-to-epithelial transition of human lung fibrosarcoma cells. Cancer Res 67: 4236-4243, 2007.

36. Funasaka T, Hogan V and Raz A: Phosphoglucose isomerase/ autocrine motility factor mediates epithelial and mesenchymal phenotype conversions in breast cancer. Cancer Res 69: 5349-5356, 2009.

37. Kugler W, Breme K, Laspe P, et al: Molecular basis of neurological dysfunction coupled with haemolytic anaemia in human glucose-6-phosphate isomerase (GPI) deficiency. Hum Genet 103: 450-454, 1998.

38. Yanagawa T, Funasaka T, Tsutsumi S, Hu H, Watanabe $\mathrm{H}$ and Raz A: Regulation of phosphoglucose isomerase/autocrine motility factor activities by the poly(ADP-ribose) polymerase family-14 Cancer Res 67: 8682-8689, 2007.

39. Nakano H, Tateishi A, Miki H, et al: Hyperthermic isolated regional perfusion for the treatment of osteosarcoma in the lower extremity. Am J Surg 178: 27-32, 1999.

40. Williams RR, Hassan-Walker AF, Lavender FL, Morgan M, Faik P and Ragoussis J: The minisatellite of the GPI/AMF/NLK/ MF gene: interspecies conservation and transcriptional activity. Gene 269: 81-92, 2001.

41. Funasaka T, Yanagawa T, Hogan V and Raz A: Regulation of phosphoglucose isomerase/autocrine motility factor expression by hypoxia. FASEB J 19: 1422-1430, 2005.

42. Khalil AA, Kabapy NF, Deraz SF and Smith C: Heat shock proteins in oncology: diagnostic biomarkers or therapeutic targets? Biochim Biophys Acta 1816: 89-104, 2011.

43. Jego G, Hazoumé A, Seigneuric R and Garrido C: Targeting heat shock proteins in cancer. Cancer Lett: Nov 13, 2010 (Epub ahead of print).

44. Uozaki H, Horiuchi H, Ishida T, Iijima T, Imamura $\mathrm{T}$ and Machinami R: Overexpression of resistance-related proteins (metallothioneins, glutathione-S-transferase pi, heat shock protein 27, and lung resistance-related protein) in osteosarcoma. Relationship with poor prognosis. Cancer 79: 2336-2344, 1997.

45. Moon A, Bacchini P, Bertoni F, et al: Expression of heat shock proteins in osteosarcomas. Pathology 42: 421-425, 2010.

46. Têtu B, Lacasse B, Bouchard HL, Lagacé R, Huot J and Landry J: Prognostic influence of HSP-27 expression in malignant fibrous histiocytoma: a clinicopathological and immunohistochemical study. Cancer Res 52: 2325-2328, 1992. 